\title{
FORMULAÇÃO DE MEIOS DE CULTIVO À BASE DE SORO DE LEITE PARA A PRODUÇÃO DE GOMA XANTANA POR $X$. campestris $\mathrm{C}_{7} \mathrm{~L}^{1}$
}

\author{
Marcia NITSCHKE ${ }^{2 *}$, Vanessa RODRIGUES ${ }^{3}$, \\ Lisiane Fiorio SCHINATTO ${ }^{4}$
}

\begin{abstract}
RESUMO
A goma xantana é um polissacarídeo microbiano de grande significado comercial especialmente para a indústria de alimentos. O objetivo deste trabalho foi avaliar a produção de xantana em diferentes meios de cultura à base de soro de leite utilizando o isolado Xanthomonas campestris $\mathrm{C}_{7} \mathrm{~L}$. Dentre as formulações testadas o meio de soro de leite integral produziu maior viscosidade e concentração final de xantana. Um sistema combinando soro integral $(0,35 \%$ de proteína) e soro filtrado $(0,18 \%$ de proteína) foi proposto. Na primeira fase em soro integral a produção de xantana foi de $13 \mathrm{~g} / \mathrm{L}$ e $45 \%$ de rendimento,enquanto que na segunda fase utilizando-se soro filtrado obteve-se um total de $28 \mathrm{~g} / \mathrm{L}$ de xantana e $75 \%$ de rendimento. O rendimento geral do processo foi de $55 \%$ e a viscosidade final do meio atingiu $18000 \mathrm{cP}$. As soluções de xantana produzidas em soro de leite apresentaram comportamento pseudoplástico e tixotrópico característicos deste tipo de polímero. $\mathrm{O}$ isolado $\mathrm{C}_{7} \mathrm{~L}$ demonstrou capacidade de produzir gomas de alta viscosidade e qualidade em soro de leite, constituindo uma alternativa promissora para a produção industrial de goma xantana a partir deste subproduto.
\end{abstract}

Palavras- chave: xantana; soro de leite; Xanthomonas campestris

\section{SUMMARY}

FORMULATION OF WHEY-BASED MEDIA FOR XANTHAN GUM PRODUCTION BY $X$. campestris $C_{7}$ L ISOLATE. Xanthan gum is a microbial polysaccharide of great commercial interest, especially in the food industry. The aim of this work was the evaluation of xanthan gum production from different whey - based media by a lactose utilizing Xanthomonas campestris $\mathrm{C}_{7} \mathrm{~L}$ isolate. Three whey media formulations were tested: unfiltered whey, filtered whey and hydrolyzed whey. The medium composed of unfiltered whey showed the highest viscosities and xanthan concentrations. A two stage fermentation strategy, combining unfiltered whey $(0,35 \%$ protein) and filtered whey $(0,18 \%$ protein), was proposed. The first stage, using unfiltered whey medium, showed a xanthan production of $12 \mathrm{~g} / \mathrm{L}$ and a $45 \%$ yield. The second stage, with filtered whey addition, gave final xanthan concentration of $28 \mathrm{~g} / \mathrm{L}$ and a $75 \%$ yield. The overall yield was $55 \%$ and final broth viscosity reached $18000 \mathrm{cP}$. The polymer produced in this combining system showed typical pseudoplastic and thixotropic behavior. The $X$. campestris $\mathrm{C}_{7} \mathrm{~L}$ isolate produced high viscosity broths and high quality gums when using whey as substrate and constitutes a promising option for the industrial production of xanthan gum from whey.

Keywords: xanthan; whey; Xanthomonas campestris

$\overline{{ }^{1} \text { Recebido para publicação em 12/09/00. Aceito para publicação }}$ em 06/03/01.

2 UNICAMP-FEA - Departamento de Ciência de Alimentos- Laboratório de Bioquímica. Cx Postal 6121 CEP 13083-970 Campinas $-S P$

${ }^{3}$ Centro de Pesquisa em Alimentação (CEPA) - UPF - Passo

Fundo, $R S$

${ }^{4}$ Estudante do Curso de Farmácia - UPF- RS

${ }^{*}$ A quem a correspondência deve ser enviada.

\section{1 - INTRODUÇÃO}

A goma xantana é um polissacarídeo microbiano produzido por linhagens de Xanthomonas campestris. Pelo fato de possuir propriedades reológicas únicas, a xantana vem sendo amplamente utilizada como agente suspensivo, espessante, emulsionante e estabilizante principalmente na indústria de alimentos $[9,20]$. A xantana também encontra aplicação em uma grande variedade de processos industriais, sendo aplicada em grande escala na recuperação secundária e terciária do petróleo [3].

Devido ao mercado crescente, muitos estudos têm sido conduzidos objetivando o melhoramento das linhagens, dos meios de cultivo e dos processos de extração e purificação de goma xantana. A maior parte da literatura referente à produção de xantana cita o uso de glicose e sacarose como fontes de carbono preferenciais [11,17], entretanto algumas fontes alternativas têm sido sugeridas $[1,24]$, visando principalmente o aproveitamento de resíduos industriais e diminuição nos custos de produção. O soro de leite, resultante da fabricação de queijos, vem sendo estudado como alternativa $[15,16,18,21]$. A produção diária de soro de leite atinge quantidades muito elevadas e seu descarte representa um sério problema ambiental [21], entretanto possui alto teor de lactose além de proteínas, e sais minerais constituindo um meio de cultura rico e de fácil obtenção. O principal problema encontrado na produção de xantana em soro de leite é a baixa capacidade de utilização de lactose por $X$. campestris, fato este que se deve à baixa afinidade da b-galactosidase da bactéria por lactose [6]. A utilização de linhagens genéticamente modificadas também foi proposta $[8,13,23]$ porém, as culturas demonstraram pouca estabilidade e gomas de qualidade inferior. Em estudo anterior foi relatada a seleção de isolados selvagens de $X$. campestris com capacidade para a produção de xantana a partir de lactose [12]. O presente trabalho teve por objetivo estudar diferentes formulações de meios de cultura à base de soro de leite, visando a utilização deste subproduto, para a produção de xantana pelo isolado $X$. campestris $\mathrm{C}_{7} \mathrm{~L}$.

\section{2 - MATERIAL E MÉTODOS}

\section{1 - Microrganismo}

Utilizou-se o isolado Xanthomonas campestris $\mathrm{C}_{7} \mathrm{~L}$ obtido em trabalho anterior [12]. 


\section{2 - Meios de cultura}

Para a manutenção do isolado utilizou-se meio mínimo de lactose contendo 1,5\% lactose, 0,5\% $\mathrm{K}_{2} \mathrm{HPO}_{4}$, $0,2 \% \mathrm{NH}_{4} \mathrm{Cl}, 0,1 \% \mathrm{NaCl}, 0,01 \% \mathrm{MgSO}_{4}$ e $0,1 \%$ extrato de levedura $(\mathrm{pH} 7,0-7,2)$. O soro em pó foi cedido gentilmente pela ELEGE Alimentos LTDA ( Porto Alegre, RS), tendo na sua composição $1,0 \%$ gordura, $76,81 \%$ lactose, $12,03 \%$ proteína, $8,67 \%$ sais minerais e $0,065 \%$ ácido lático.

Meio de soro de leite integral: solução aquosa a $4 \%(\mathrm{p} / \mathrm{v})$ de soro de leite em pó, $\mathrm{MgSO}_{4}$ 0,01\% e $\mathrm{K}_{2} \mathrm{HPO}_{4}$ $0,5 \%(\mathrm{pH} \mathrm{7,2)}$. Após a autoclavagem o meio de soro apresentou um aspecto bastante turvo permanecendo com as proteínas insolúveis.

Meio de soro filtrado : foi preparado meio de soro integral que após a esterilização em autoclave foi filtrado assepticamente, obtendo-se um meio de aspecto límpido (proteínas precipitadas durante autoclavagem foram eliminadas).

Meio de soro de leite hidrolisado : preparou-se soro integral adicionando-se b-galactosidade (Lactozim 3000L HP-G, Novo Nordisk) nas condições especificadas pelo fabricante.

\section{3 - Inóculo e condições de cultivo}

O inóculo foi preparado a partir de um tubo de ágar inclinado em meio lac-min [16]. Uma alça contendo cultura de 24 horas foi inoculada em tubo de ensaio contendo $5 \mathrm{~mL}$ de caldo lac-min e incubado em agitador rotatório por 24 horas a $160 \mathrm{rpm}$ e $28^{\circ} \mathrm{C}$ num ângulo de inclinação de aproximadamente $30^{\circ}$. A cultura resultante $(10 \mathrm{~mL})$ foi transferida para erlenmeyer de $500 \mathrm{~mL}$ contendo $90 \mathrm{~mL}$ do respectivo meio de soro e incubada novamente por 72 horas à $200 \mathrm{rpm}$ e $28^{\circ} \mathrm{C}$.

\section{4 - Sistema alimentado}

O ensaio combinando dois tipos de meio (soro integral e soro filtrado) foi conduzido em fermentador de 16L (New Brunswick SF-116) contendo inicialmente 6L de meio de soro integral. O inóculo foi preparado como anteriormente e adicionado na proporção de $10 \%(\mathrm{v} / \mathrm{v})$ do volume total de meio. A temperatura foi mantida em $30^{\circ} \mathrm{C}$, aeração $1 \mathrm{vvm}, \mathrm{pH}$ controlado automaticamente para 7,0 e a velocidade de agitação foi programada para manter o oxigênio dissolvido (DO) $>50 \%$. Quando a concentração de lactose no meio atingiu aproximadamente $3 \mathrm{~g} / \mathrm{L}$ adicionou-se assepticamente $1 \mathrm{~L}$ de soro de leite filtrado preparado na concentração de $20 \%(p / v)$.

\section{5 - Determinações analíticas}

A concentração de lactose e açúcares redutores totais (ART) foram determinadas pelo método do ácido dinitrosalicílico (DNS). A glicose foi determinada por método enzimático (Glicose oxidase- Ecoline 250- Merck). $O$ teor de galactose foi determinado enzimaticamente (lactose/D-galactose -Boehringer Mannheim). Proteína por nitrogênio total (Kjeldahl).
Para a determinação de xantana uma alíquota do meio foi diluída em água destilada (10x) e centrifugada $(13000 \times \mathrm{g})$. O sobrenadante foi adicionado de $1 \%$ de $\mathrm{KCl}$ agitado em agitador magnético por 15 minutos e adicionado de três volumes de álcool etílico $96^{\circ}$ para a precipitação da goma. $\mathrm{O}$ produto obtido foi filtrado à vácuo, seco em estufa $55^{\circ} \mathrm{C}$ por 12 horas e colocado em dessecador à temperatura ambiente até peso constante. A viscosidade dos meios de cultivo foi determinada em viscosímetro Brookfield tipo Cone/Plate spindle $\mathrm{CP}-52,0.6 \mathrm{rpm}$ à $25^{\circ} \mathrm{C}$. Para estudo de reologia procedeu-se a purificação da xantana: a goma foi redissolvida a $1 \%$ em água destilada, novamente centrifugada (13000xg). O sobrenadante foi filtrado em membrana tipo Millipore $(0,45 \mathrm{~mm})$ e adicionado de 3 volumes de álcool etílico $96^{\circ}$. O precipitado foi submetido à secagem em estufa $\left(55^{\circ} \mathrm{C}\right)$ e moagem e mantido em dessecador. Preparou-se uma solução aquosa a $1 \%$ da goma purificada adicionada de $0,1 \%$ de $\mathrm{KCl}$. As viscosidades foram medidas a $25^{\circ} \mathrm{C}$ em viscosímetro Brookfield LVTDV-II usando spindle número 3, sob diferentes taxas de cizalhamento. Todas as determinações foram realizadas em triplicata.

\section{3 - RESULTADOS E DISCUSSÃO}

Na Tabela 1 são mostrados os resultados da produção de xantana pelo isolado $\mathrm{C}_{7} \mathrm{~L}$ em 3 tipos diferentes de formulações à base de soro de leite. Observa-se que o meio de soro integral apresentou maior viscosidade final em relação aos outros meios testados. Este fato sugere que a goma produzida em soro integral apresenta maior qualidade ou seja, maior viscosidade gerada por unidade de polímero produzido, enquanto que em meio de soro filtrado a xantana produzida possui qualidade inferior ou seja, menor viscosidade gerada por unidade de polímero produzido.

TABELA 1. Comparação dos resultados obtidos em diferentes meios de soro de leite.

\begin{tabular}{cccc}
\hline Tipo de soro & Xantana $(\mathrm{g} / \mathrm{Kg})$ & Viscosidade final (cP) & Rendimento $(\%)^{*}$ \\
\hline Hidrolisado & 12,21 & 6162 & 43 \\
Integral & 14,7 & 9506 & 55 \\
Filtrado & 11,8 & 2030 & 51
\end{tabular}

* xantana produzida /açúcar consumido $\times 100$

No soro hidrolisado observou-se uma preferência pelo uso de glicose e galactose em relação à lactose presente no meio, entretanto este fato não se refletiu em maior produção de xantana. Cabe ressaltar, que o microrganismo utilizou glicose e galactose concomitantemente, não exibindo preferência por um desses açúcares. A lactose residual foi consumida mais lentamente e preferentemente na fase de acúmulo de polímero ( $F i$ gura 1). SCHWARTZ e BODIE [16] utilizando um isolado adaptado à lactose, verificaram que, quando a glicose foi adicionada a um meio contendo soro de leite, a lactose deixava de ser utilizada. $\mathrm{O}$ isolado $\mathrm{C}_{7} \mathrm{~L}$ não demonstrou preferência estrita por glicose (e ou galactose), ou seja, utilizou a lactose mesmo na presença dos monossacarídeos, principalmente a partir de 48 horas de cultivo, quando se inicia a produção de 
xantana, indicando a adaptação deste microrganismo à utilização de lactose para a produção do polissacarídeo.

FIGURA 1. Perfil de consumo de açucares em soro de leite hidrolisado por $X$. campestris $\mathrm{C}_{7} \mathrm{~L}$

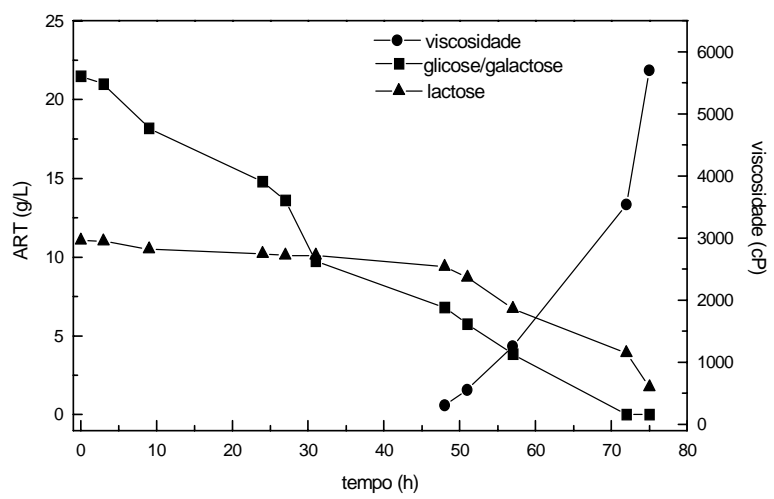

A relação $\mathrm{C} / \mathrm{N}$ no meio de cultura influencia grandemente a produção de xantana. Segundo Sutherland [19], uma elevada concentração de nitrogênio é necessária para um rápido crescimento celular entretanto, quando a concentração de nitrogênio no meio de cultura for muito elevada, a xantana produzida possui propriedades reológicas inadequadas [2].

Meios contendo elevado teor de fonte de carbono e baixo teor de nitrogênio favorece o acúmulo de polímero [4]. Em geral os processos industriais procuram utilizar meios que disponibilizem condições tanto para o crescimento como para o acúmulo de goma [22]. De VUYST, VAN-LOO, VANDAMME [5] verificaram que a xantana é produzida como metabólito secundário e propuseram a dissociação do processo em duas fases distintas: a fase de crescimento, onde maior concentração de nitrogênio é requerida para o crescimento celular e a fase de produção, onde maior concentração de carbono é necessária, visando o acúmulo de produto [10]. Baseado nesses fatos, propôs-se um sistema combinado em duas etapas utilizando soro integral $(0,35 \%$ proteína) na primeira etapa e soro filtrado ( $0,18 \%$ proteína) na segunda etapa.

A Figura 2 mostra os resultados da produção de xantana no sistema combinado.

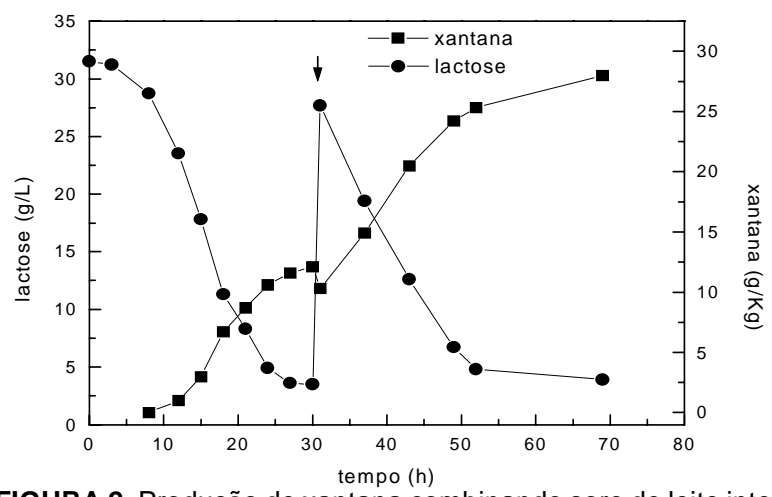

FIGURA 2. Produção de xantana combinando soro de leite integral e filtrado.
Na primeira etapa obteve-se $13 \mathrm{~g} / \mathrm{Kg}$ de xantana e um rendimento de $45 \%$. Após 30 horas de processo a adição de soro filtrado produziu $28 \mathrm{~g} / \mathrm{Kg}$ de xantana e um rendimento de $75 \%$. Depois de 70 horas o rendimento total atingiu 55\% e a viscosidade final do meio foi de $18000 \mathrm{cP}$. No início do processo, o uso do soro integral favoreceu o crescimento celular, enquanto que na segunda fase, a adição de soro filtrado contendo menor concentração de proteínas favoreceu o acúmulo do produto. De fato, a relação $\mathrm{C} / \mathrm{N}$ do meio parece ser o fator mais importante na produção de xantana , uma vez que a adição de soro integral na segunda etapa também mostrou concentrações de xantana e rendimento semelhante aos encontrados na primeira etapa. Por outro lado, a utilização de soro filtrado na primeira etapa mostrou produções de gomas de baixa viscosidade (Tabela 1).

Para a caracterização reológica da goma xantana produzida em soro de leite, verificou-se a influência da taxa de cizalhamento na viscosidade do polímero ( Figura 3). Observa-se um comportamento pseudoplástico ou seja, diminuição da viscosidade à medida que aumenta a taxa de cizalhamento. Este comportamento é típico de soluções de xantana. Observa-se leve comportamento tixotrópico, que também foi relatado por SANDFORD et al [14] que relacionaram o comportamento tixotrópico com o conteúdo de piruvato presente na xantana. Gomas com elevado teor de piruvato exibiram leve comportamento tixotrópico, enquanto gomas com baixo teor de piruvato, não demonstraram esse comportamento. Sabe-se, que o conteúdo de piruvato é um indicativo da qualidade da goma xantana [7] portanto, os resultados obtidos sugerem que a goma xantana produzida em soro de leite possui características reológicas adequadas a um produto de boa qualidade. Entretanto, futuros testes devem ser conduzidos visando a melhor caracterização química e reológica da xantana produzida pelo isolado $\mathrm{C}_{7} \mathrm{~L}$ em soro de leite.

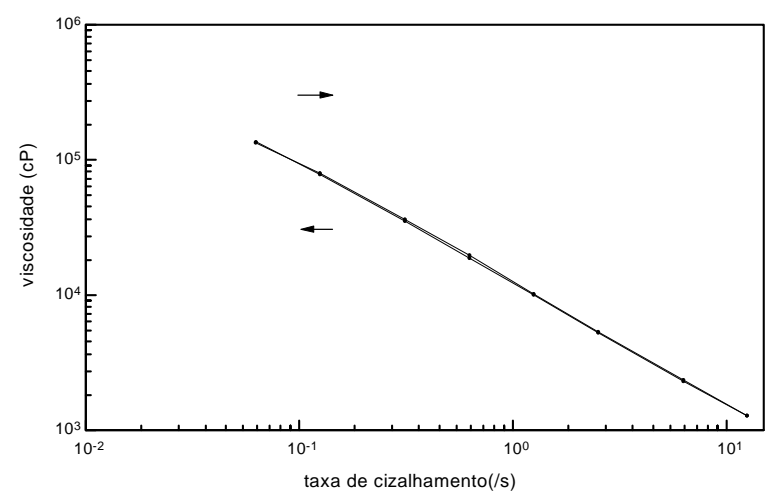

FIGURA 3. Reograma de soluções à $1 \%$ de xantara produzida em soro de leite

\section{4 - CONCLUSÕES}

- O meio de cultura à base de soro de leite integral demonstrou os melhores resultados dentre os meios testados. 
- Em soro de leite hidrolisado, a partir de 48 horas de cultivo, o isolado $C_{7} \mathrm{~L}$ demonstrou capacidade de utilização de lactose independente da presença de glicose e galactose.

- A estratégia de combinar meio à base de soro de leite integral e filtrado aumentou o rendimento e a concentração final de xantana.

- A xantana produzida em meios de soro de leite exibiu comportamento pseudoplástico e tixotrópico característicos.

- o isolado Xanthomonas campestris $C_{7} L$ possui capacidade para utilização do soro de leite como substrato constituindo uma alternativa promissora para a produção de goma xantana a partir deste resíduo.

\section{5 - REFERÊNCIAS BIBLIOGRÁFICAS}

[1] BILANOVIC, D.; SHELEF, G.; GREEN, M. Xanthan fermentation of citrus waste. Bioresource Technology, v.48, n.2, p.169-172, 1994.

[2] CASAS, J.A.; SANTOS, V.E.; GARCIA-OCHOA, F. Xanthan gum production under several operational conditions: molecular structure and rheological properties. Enzyme and Microbial Technology, v.26, n.2-4, p.282-291, 2000.

[3] COTTRELL, I.W.; KANG, K. S. Xanthan gum, a unique bacterial polysaccharide for food applications. Developments in Industrial Microbiology ,v.19, p.117-131, 1978.

[4] DAVIDSON, I.W. Production of polysaccharide by $X$. campestris in continuous culture. FEMS Microbiological Letters, v.3, n.6, p.347-349, 1978.

[5] DE VUYST, L. ; VAN-LOO, J.; VANDAMME, E.J. Two-step fermentation process for improving xanthan production by Xanthomonas campestris NRRL B-1549. Journal of Chemical Technology and Biotechnology , v.39, n.4, p.263-273, 1987.

[6] FRANK, J.F.; SOMKUTI, G. A .General properties of betagalactosidase of Xanthomonas campestris. Applied and Environmental Microbiology, v.38, n.3, p.554-556, 1979.

[7] FLORES CANDIA, J.L.; DECKWER, W.D. Effect of the nitrogen source on pyruvate content and rheologial properties of xanthan. Biotechnology Progress, v.15, n.3, p.446452, 1999.

[8] FU, J.F.; TSENG, Y.H. Construction of a lactose -utilizing Xanthomonas campestris and production of xanthan gum from whey. Applied and Environmental Microbiology, v.56, n.4, p.919-923, 1990.

[9] KATZBAUER, B. Properties and applications of xanthan gum. Polymer Degradation and Stability, v.59, p.81-84, 1998.

[10] LO,Y.M.; YANG, S.T.; MIN, D.B. Effects of yeast extract and glucose on xanthan production and cell with in batch culture of Xanthomonas campestris. Applied Microbiology and Biotechnology, v.47, n.6, p.689-694,1997.

[11] MARGARITIS, A.; PACE, G.W. Microbial polysaccharides. In: MOO-YOUNG, M.(Ed) Comprehensive
Biotechnology. Oxford: Pergamon Press, 1985, p.10061041.

[12] NITSCHKE, M.; THOMAS, R.W.S.P.; KNAUSS, C. Xanthan production by Xanthomonas campestris in a whey -based medium. Revista de Microbiologia , v. 28, p. 148-151, 1997.

[13] PAPOUTSOPOULOU, S.V.; EKATERINIADOU, L.V.; KYRIAKIDIS, D. A . Genetic construction of Xanthomonas campestris and xanthan gum production from whey. Biotechnology Letters, v.16, n.12, p.1235-1240, 1994.

[14] SANDFORD, P.A.; PITTSLEY, J.E.; KNUTSON, C.A .; WATSON, P.R.; JEANES, A . Variation in Xanthomonas campestris NRRL B-1459: characterization of xanthan products of differing pyruvic acid content. In: SANDFORD, P.A.; LASKIN, A. (Eds). Extracellular Microbial Polysaccharides. Washington: American Chemical Society, 1977, p.192-210.

[15] SCHWARTZ, R.D.; BODIE, E.A. Production of high-viscosity whey broths by a lactose-utilizing Xanthomonas campestris strain. Applied and Environmental Microbiology ,v.50, n.6, p.1483-1485, 1985.

[16] SCHWARTZ, R.D.; BODIE, E.A. Production of high-viscosity whey- glucose broths by a Xanthomonas campestris strain. Applied and Environmental Microbiology, v.51, n.1, p.203-205, 1986.

[17] SOUW, P.; DEMAIN, A .L. Nutritional studies on xanthan production by $X$. campestris NRRL B-1459. Applied and Environmental Microbiology, v.37, n.6, p.1186-1192, 1979.

[18] STAUFFER, K.R. ; LEEDER, J.G. Extracellular microbial polysaccharide production by fermentation on whey or hydrolyzed whey. Journal of Food Science , v.43, n. 3, p. $756-758,1978$.

[19] SUTHERLAND, I.W. Biosynthesis of microbial exopolysaccharides. Advances in Microbial Physiology , v.23, p.79-149, 1982

[20] SYMES, K.C. The relation between the covalent structure of the Xanthomonas polysaccharide (xanthan) and its function as a thickening, suspending and gelling agent. Food Chemistry, v.6, n.1, p.63-76, 1980.

[21] THORNE, L. ; TANSEY, L.; POLLOCK, T.J. Direct utilization of lactose in clarified cheese whey for xanthan gum synthesis by Xanthomonas campestris . Journal of Industrial Microbiology , v.3, n.5, p.321-328, 1988.

[22] VASHITZ, O; SHEINTUCH, M. Analysis of polymer synthesis rates during steady-state growth of $X$. campestris . Biotechnology and Bioengineering, v.37, n.4, p.383385, 1991.

[23] WALSH, P.M.; HAAS, M. J.; SOMKUTI, G. A . Genetic construction of lactose-utilizing Xanthomonas campestris. Applied and Environmental Microbiology , v.47, n.2, p. 253-257,1984.

[24] YOO, S.D.; HARCUM, S.W. Xanthan gum production from waste sugar beet pulp. Bioresource Technology, v.70, n.1, p.105-109, 1999 